\title{
Designing and implementing unemployment benefit systems in middle and low income countries: beyond risk-pooling vs savings
}

\author{
David A Robalino and Michael Weber
}

\author{
* Correspondence: \\ mweber1@worldbank.org \\ World Bank, 1818 H Street, NW, \\ Washington, DC 20433, USA
}

\begin{abstract}
Several middle income countries are considering reforms to their severance pay regulations to both increase flexibility for firms and better protect workers. Policy discussions then often revolve around whether to adopt an unemployment insurance $(\mathrm{UI})$ scheme or unemployment individual savings accounts (UISAs). Proponents of the first emphasize its ability to pool risks and introduce an element of solidarity. Critics point to its potentially negative effects on labor supply as individuals could have fewer incentives to seek, take or keep jobs. In this paper, we show that UI and UISAs are, in fact, particular cases of a more general design and that the crucial policy choice is in terms of how redistribution - to cover benefits for those who could not save enough -- is financed. We outline key features of this general design and identify trade-offs and possible solutions. We then discuss issues related to implementation and show how recent technological developments around biometric identification can facilitate the monitoring of conditionalities related to participation in job-search and training activities.
\end{abstract}

JEL codes: 015, J64, H55

Keywords: Unemployment benefits; Unemployment insurance; Savings accounts; Risk-pooling; Labor market transitions

\section{Introduction}

As part of the objective of achieving more flexibility for employers while better protecting workers, several countries have been considering the adoption (or reform) of unemployment benefit systems. Policy discussions then often revolve around the question of whether to adopt an unemployment insurance (UI) scheme or unemployment individual savings accounts (UISAs). Proponents of the first emphasize its ability to pool risks and introduce an element of solidarity. Critics highlight its potentially negative effects on labor supply as individuals would have fewer incentives to seek, take or keep jobs. The evidence, which comes mainly from OECD countries, is in general mixed. ${ }^{1}$ (There are various studies for high income countries showing that unemployment spells and the unemployment rate tend to increase as the level of benefits and/or their duration increases (see Ribe et al. 2012; chapter 5, Lalive 2008, or Lalive et al. 2005). Chetty $(2004,2008)$ and Chetty and Looney (2006) reveal a welfare increasing income effect of unemployment benefits which is particularly important in the presence of inefficient private insurance markets and high risk aversion. Chetty 
(2004, 2008) highlights that the income effect is significant for liquidity constrained households, since unemployment benefits increase the opportunity for consumption while unemployed. This, in turn, reduces the need for job search which leads to a substitution effect. If workers are unconstrained, this income effects is broadly not existing. The substitution effect and the income effect have contrasting welfare implications (see Chetty and Looney 2006). At the same time, more generous benefits can give workers more flexibility to search for jobs and lead to better matches. Recent analysis for European countries confirm this argument Tatsiramos (2009).

Unemployment individual savings accounts have both, proponents and opposers. The main advantage over UI which has been emphasized in the literature is that, because benefits are financed out of individuals' savings, workers have better incentives to seek and take jobs (Robalino et al. 2009). Indeed, balances in the individual account can, under certain conditions, be used to finance investments such as education or the purchase of a house, or to increase the pension's value upon retirement. The main criticism, however, is that in their pure form they do not provide enough protection to workers, particularly low skilled workers who tend to have shorter contributions densities (and therefore lower savings) and might have more frequent periods of unemployment. The fact that benefits are often paid as a lump sum can also be problematic as there is a risk that workers over consume and run out of savings before having found a job. In addition, since benefits are financed only out of savings, contributions rates are usually high (e.g., 8 percent to finance one month of unemployment benefits after 12 months of contributions) and this can reduce incentives to enroll or game the system. Below market interest rates on savings can have the same effect, particularly when access to credit is constrained and individuals cannot 'dis-save'. In the case of Brazil, for instance, there is evidence of increases in turnover as workers try to cash-out part of the savings in their accounts (World Bank 2009).

In this paper we argue that UI and UISAs are, in fact, particular cases of a more general design and that the key policy choice is in terms of how redistribution is financed. Indeed, as in the case of UISAs, unemployment insurance programs also rely on some type of individual accounting since it is necessary to track contributions (which condition eligibility for benefits) as well as the payment of benefits (to assess when to terminate them). The essential difference between the two systems is that in the case of UI any positive balance in the accounts is taxed at a 100 percent rate. It is the revenue from this implicit tax that is used to subsidize the accounts with negative balances allowing the system to guarantee a certain level of benefits during a given period of time, regardless of the level of individual contributions accumulated in the account. In the case of UISAs the savings in the accounts are not taxed, but the level of protection is lower - many workers will only be able to finance a couple of months of unemployment benefits. To address this problem, countries such as Chile have created a 'solidarity fund' to top up the savings of the most vulnerable workers. In the Chilean case, the solidarity fund is financed by a combination of pay-roll taxes and general taxes. However, this is just one possible form of taxation. An alternative form of UISA could tax savings instead and decrease the payroll tax. This might reduce the incentives to save and, thus, find or keep jobs but as long as the tax is below 100 percent the incentives will be stronger than in the case of a pure UI system. We argue that making these policy choices explicit opens a broader range of possibilities for the design and implementation of unemployment benefit programs in middle and low income countries; designs that can create a better balance between incentives and protection. 
The paper is organized in five sections. In the next section, we provide a brief overview of unemployment benefit arrangements around the world to set the context. The section that follows introduces UI and UISAs as part of a more general design and identifies the key policy parameters that need to be chosen to create a continuum between the two systems. A continuum along which incentives for work and levels of protection move in opposite directions. The next two sections focus on the design and implementation of UB systems in middle and low income countries respectively. In terms of design we provide guidelines to set the mandate of the system (benefits and duration) and how to assess the tradeoffs between alternative mechanisms to finance redistribution. Regarding implementation, the focus is on institutional arrangements to manage the scheme; the types of conditionalities to pay benefits that need to be considered and enforcement mechanisms; and mechanisms to contract and pay providers of services. The paper ends with a short summary of its main messages and policy implications.

\section{How do countries manage unemployment risks?}

Similar to other insurance programs, unemployment benefit systems can either rely on risk-pooling or savings arrangements. In traditional risk pooling arrangements, benefits are not linked to individuals' contributions; benefits can be financed by the contributions of other members within the pool or a third party. ${ }^{2}$ The two types of risk-pooling arrangements in the case of unemployment benefits are severance pay (where the employers pools the risk and finances the scheme) ${ }^{3}$ and traditional unemployment insurance (where workers contribute to a common pool or fund that then pays the benefits of those who become unemployed). At the other extreme, in the case of unemployment individuals' savings accounts (UISAs), workers self-insure based on their contributions and those of their employers. As discussed below, most countries that rely on savings arrangement also have a risk-pooling scheme either in the form of severance pay, a "solidary fund" that tops up the savings of vulnerable workers, or like in the case of Brazil classic unemployment insurance.

The most common income support systems for the unemployed are severance pay and unemployment insurance. Around the world, out of 183 countries for which data are available, 77 percent have severance pay and 42 percent unemployment insurance. Only a few countries, mainly in Latin America have adopted unemployment individual savings accounts (UISA) with or without a solidarity component. A minority of countries also has explicit redistributive arrangements (unemployment assistance) to protect the unemployed. It is interesting to observe that more than half of the countries have two or more unemployment benefit schemes - particularly developed countries.

Low-income countries tend to have more generous ${ }^{4}$ severance pay systems (see Figure 1). Indeed, while the average generosity of low income countries is highest among all income groups, it also varies greatly and increases with GDP per capita. ${ }^{5}$ For example, Burundi and Togo have a low severance pay generosity of 1 and 1.6 respectively with a GDP per capita of 271 and 588 USD. In contrast, both, Ghana and Zambia have a generosity value of 8.7 with a GDP per capita of 1,570 and 1,425 USD respectively for 2011. OECD countries, however, have a decreasing severance pay generosity with increasing GDP per capita. Greece and Portugal, for example, 


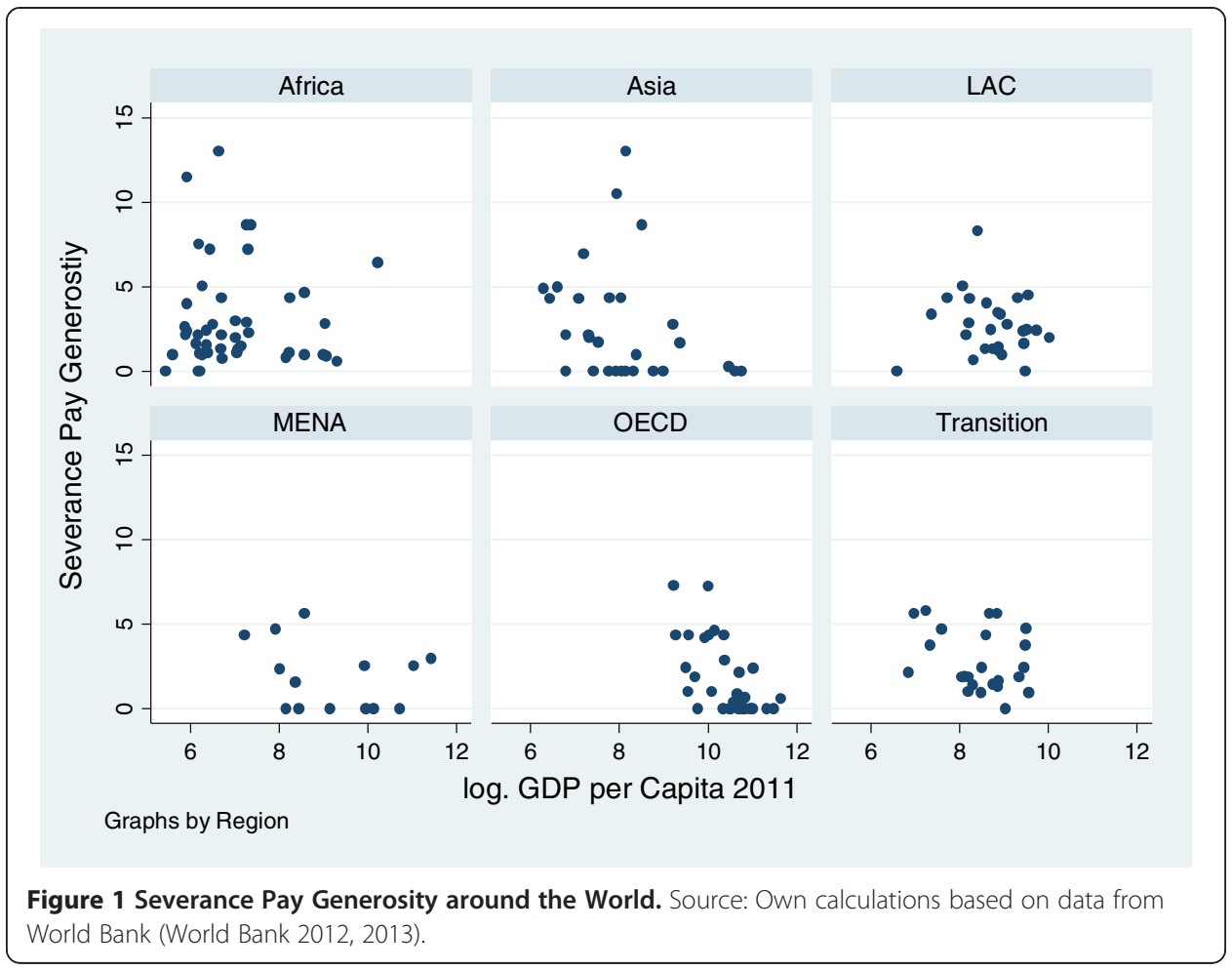

have generosity levels of 4.6 and 7.2 respectively with a GDP per capita of 25,622 and 22,316. Canada, in contrast, has a generosity value of 0.7 with a GDP per capita of 50,345 USD for 2011. Similarly, Ireland has a severance pay generosity of 0.6 with a GDP per capita of 48,423USD for 2011. Overall, OECD countries with a higher GDP per capita tend to have less generous systems.

The presence of UI is strongly related to the level of development. Around 77 percent of the high income and 52 percent of the upper middle income countries feature UI. In contrast, out of 32 low income countries only 6 provide UI. These are Kyrgyz Republic, Liberia, Malawi, Nepal, Tajikistan, and Tanzania. Among the lower-middle income countries, merely one fourth have an UI scheme. In Sub-Saharan Africa, only 4 countries have implemented UI. In Asia, the share of countries without UI is about 81 percent, whereas it is 52 percent in Latin America and the Caribbean, and 75 percent in the Middle East and North Africa Region.

The design of unemployment insurance systems varies widely around the world in terms of the level and the duration of benefits as well as eligibility conditions. The generosity of unemployment insurance ${ }^{6}$ and assistance depends on the country's income level. Once countries provide unemployment benefits, there is a significant positive relationship between generosity and the country's income level. The highest average generosity can be found in OECD countries (around 50), followed by transition economies (around 10), and Middle East and North Africa (3), Asia (3), Latin America and the Caribbean (1.8), and Africa (0.14). Countries with very high GDP per capita such as Switzerland and Luxembourg also feature particularly high unemployment benefit generosity values ( 80 for Switzerland and 87 for Luxembourg). 


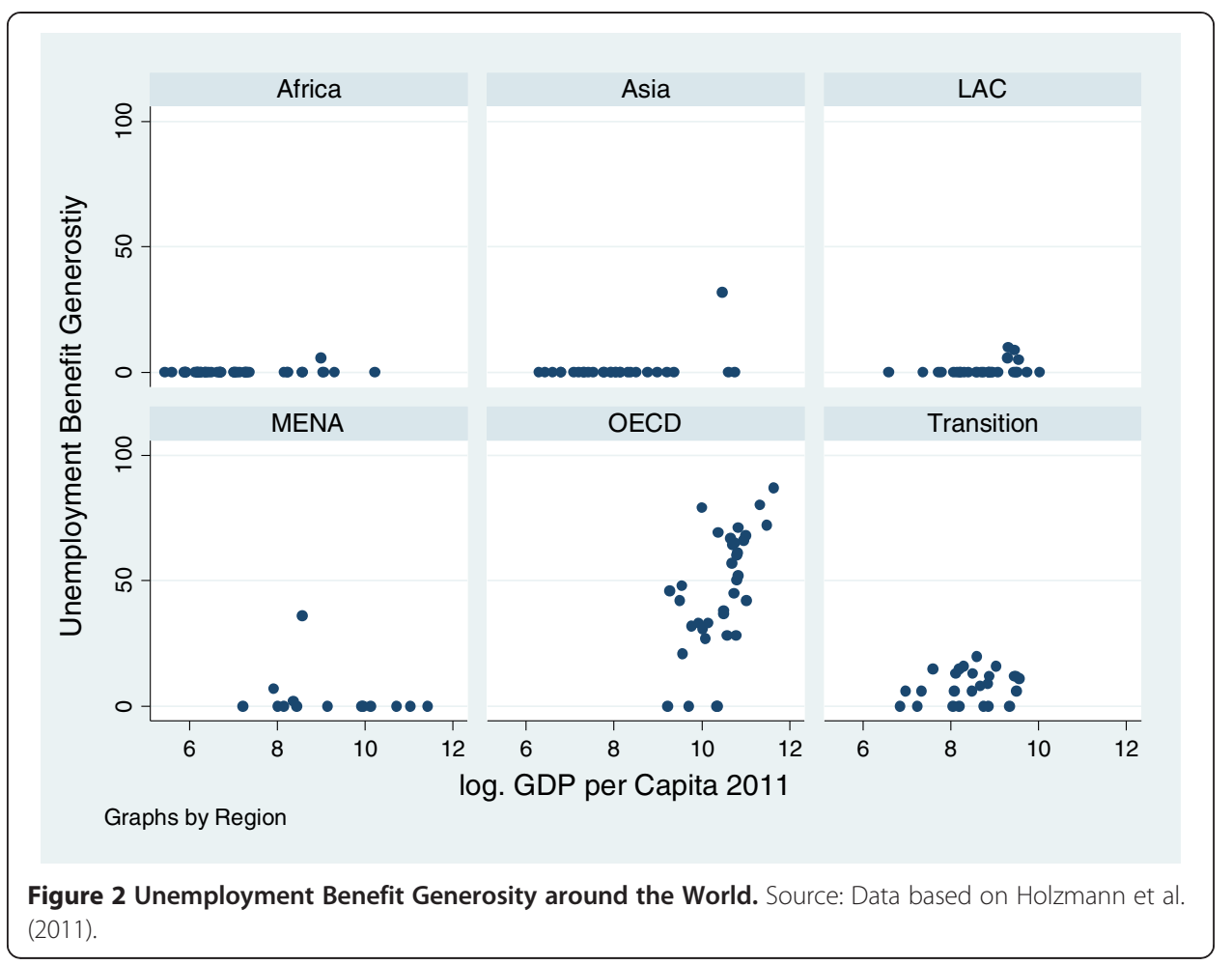

Many of the countries that are most generous have both, UI and UA systems such as the Netherlands, Spain, France, and Sweden with generosity values of 71, 69, 67, and 66 (see Figure 2). In contrast, (lower) income countries are much less generous with values of around 6 (e.g. Georgia) to 20 (e.g. China) with some outliers. For example the upper middle income country Turkey features a generosity value of around 46 .

Unemployment insurance savings accounts (UISA) are a more recent type of defined contribution system. Compared to defined contribution pensions, UISAs can be funded or pay-as-you-go. ${ }^{7}$ Most of the countries that have funded UISAs are in Latin America (e.g., Chile or Argentina). ${ }^{8}$ Outside Latin America, Austria and Jordan are among the few countries with individual savings accounts for the unemployed. The latter has linked its UISA scheme to its pay-as-you-go pension system (Figure 3).

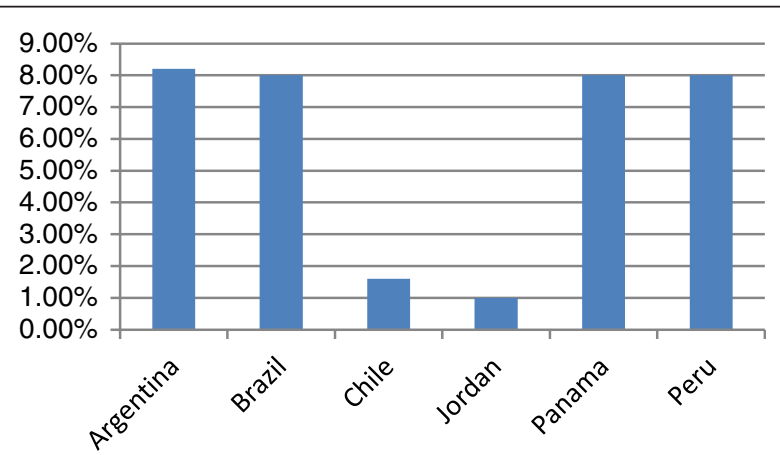

Figure 3 Contribution rates to UISA schemes. Source: Data based on Ribe et al. (2012). 


\section{$3 \mathrm{UI}$ and UISAs - Two sides of the same coin}

It is common to think that the main difference between UISAs and UI is that the former is based on individual accounts (as the name indicates) while the latter relies on a common pool. In practice, however, UI systems also require keeping track of individual accounts that register the contributions made by employers and employees to the fund, and the benefits received in the case of unemployment. These accounts, in fact, are needed for any well run social insurance program including disability or old-age pensions. The main difference between the two systems is that in the case of UI, the benefits paid are delinked from the value of the contributions made, while in UISAs the total benefits received cannot exceed the balance in the account.

Consequently, 'pure' UISAs accounts cannot be negative while accounts in traditional UI often are. The system runs because accounts with a surplus (for example the accounts of those who never become unemployed) finance accounts which have a deficit. In other words, in practice, UI works because the accounts with a positive balance are taxed at a 100 percent rate. It is this tax that contributes to reduce incentives to work. In addition, there is the subsidy received by those who were not able to contribute enough to finance their benefits. The tax and subsidy are zero in the case of UISAs and this is why the system generates better incentives.

To formalize these ideas, consider a system of $N$ workers that can be grouped into $I$ homogenous groups. Normalizing $N=1$, the size of each group is equal to their share, $s_{i}$, in the total population of workers. Members of group $i$ have the same level of human capital and therefore wages $w_{i}$ as well as the same risk, $\frac{1}{e_{i}}$, and duration, $d_{i}$ of unemployment. ${ }^{9}$ The unemployment rate, $u_{i}$, of each group is then characterized by:

$$
\frac{u_{i}}{1-u_{i}}=\frac{d_{i}}{e_{i}}
$$

A government trying to offer unemployment benefits to these workers equal to a fraction $R$ of their wages, could set small insurance pools for each group. The actuarially fair insurance premium $\alpha_{i}$ for each group would need to be set in a way that, at any point in time, expenditures are equal to revenues. We would have:

$$
\alpha_{i}=\frac{u_{i} * R}{1-u_{i}}=d_{i} * \frac{R}{e_{i}},
$$

where the last expression can be interpreted as the expected cost of unemployment benefits (the risk of unemployment $\frac{1}{e_{i}}$ times the value of the unemployment benefits).

The government can track the contributions and benefits received by each individual in the pool. On average, over time, individuals would contribute $\alpha_{i}{ }^{*} e_{i}{ }^{*} w_{i}$ when employed and cost $R^{*} d_{i} * w_{i}$ while unemployed. From equation (2), we know that $\alpha_{i}{ }^{*} e_{i}=R^{*} d_{i}$. On average, therefore, individuals within each risk pool would have accounts with zero balance. But, of course, at any point in time one would observe individuals with positive balances and individuals with negative balances. The positive balances would compensate the negative balances within the risk pool. As nobody in the pool would systematically be accumulating negative or positive balances, there are no systematic subsidies (taxes) received (paid) by any individual within the group. 
The problem is that, in practice, it is very difficult to create homogenous risks pools and charge to each a fair insurance premium. Even if administratively and statistically viable -- after all that is how car insurance works -- it would be politically difficult. As a result governments implement unemployment insurance programs with a constant premium $\alpha$, which is also calculated to equate expenditures with revenues across groups:

$$
\alpha=\frac{R * \sum s_{i} * u_{i}}{\sum s_{i} *\left(1-u_{i}\right)}=\frac{R * u}{1-u}
$$

where is $u$ is the average unemployment rate of the group of $N$ workers.

This time, individuals for whom $\alpha>\alpha_{i}$ are being taxed (i.e., are asked to pay a premium above the expected value of their unemployment benefits), in order to subsidize individuals for whom $\alpha<\alpha_{i}$ As before, the government can track the balance in the individual accounts of each plan member. On average, this balance is given by:

$$
B_{i}=\alpha * e_{i} * w_{i}-R * d_{i} * w_{i}
$$

From equation (2) above we see that individuals with $\alpha>\alpha_{i}$ would be accumulating, systematically, positive balances. These positive balances or savings, would be taxed at a 100 percent rate, to finance the negative balances of those individuals with $\alpha<\alpha_{i}$. These are the taxes on savings and the subsidies that can reduce incentives for job-search or at least allow individuals to increase their reservation wage and wait for a job for longer.

What we see so far is that once a government fixes $\alpha$ and $R$, the difference between classic unemployment insurance UI and unemployment savings accounts (UISAs) is only in terms of how to finance the accounts that have negative balances. In UI the solution is to tax savings (i.e., the balances not used to cover unemployment benefits). In UISAs savings are not taxed and either the government mobilizes resources from other types of taxes to finance negative balances or it defaults on $R$.

The key policy question therefore is not whether to adopt UI or UISAs but how to finance the redistribution within the system. There is no reason to believe that a tax on savings is more efficient than other forms of taxes.

A first comparison is between a tax on savings and a tax on wages. Indeed, the government could fix $\alpha$ (the rate at which individuals save in individual accounts), indicate that positive balances are not taxed, and then introduce a tax $t x w$ on wages for every worker to finance the accounts with negative balances.

$$
\text { txw }=\frac{\sum B_{j} * s_{j}}{\sum w_{i} * s_{i}} \text { with } j \in I: \alpha<\alpha_{j} \text { and } i \in I
$$

Over a given period individuals of any group $i$ for which $\alpha+t x w<\alpha_{i}$ would still receive subsidies from the system, but in all cases the net level of subsidies would be lower. Individuals in groups with $\alpha<\alpha_{i}$ and $\alpha+t x w>\alpha_{i}$ would lose their previous subsidy due to the new tax txw. Individuals in groups with with $\alpha>\alpha_{i}$ who were taxed under the old regime can now keep their savings. In net they receive:

$$
\begin{aligned}
& B_{i}-t x w * e_{i} * w_{i} \\
& =\alpha * e_{i} * w_{i}-R * d_{i} * w_{i}-t x w * e_{i} * w_{i} \\
& =w_{i} *\left(e_{i} *(\alpha-t x w)-R * d_{i}\right)
\end{aligned}
$$


This is greater than zero if:

$$
\alpha-\frac{R * d_{i}}{e_{i}}>t x w
$$

So as long at the new tax is below $\alpha-\alpha_{i}$ individuals within these groups $i$ would be better off. However, others with higher unemployment risks and higher $\alpha_{i}$ may not benefit.

In essence there are three important thresholds for the distribution of $\alpha_{i}: \alpha+t x w, \alpha$, and $\alpha-t x w$. The various cases are presented below.

For $\alpha+t x w<\alpha_{i}$ individuals continue to receive subsidies, the net amount is lower due to the tax.

For $\alpha<\alpha_{i}<\alpha+t x w$ individuals were receiving subsidies before and are now paying net taxes.

For $\alpha-t x w<\alpha_{i}<\alpha$ individuals are also worse off. Before they were losing the savings they generated because they paid a contribution above their actuarially fair premium. Now they can keep the savings but they have to pay a tax that represents a higher outlet than the forgone savings.

For $\alpha_{i}<\alpha-t x w$ individuals gain. They can keep their savings and the value of these savings is higher than the value of the taxes that they now have to pay.

In summary, a 100 percent tax on savings in the case a traditional UI can be replaced by an explicit tax on wages in the case of a pure UISA. Under the alternative financing mechanism incentives for job-search are likely to improve, particularly among those who have the potential to generate positive savings. Those benefiting the most from the change would be workers with a lower risk of unemployment and low actuarially fair premiums; most probably individuals with high levels of human capital. At the same time the higher tax on wages for all workers, particularly those with low levels of human capital, could increase the tax-wedge and reduce incentives to take formal sector jobs.

There are, however, other alternatives to the tax on wages that could be explored such as consumption taxes or property taxes. There is some evidence, for instance, that consumption taxes can mobilize the same amount of revenues as pay-roll taxes but with lower levels of distortion in the labor market (see Bird and Smart 2013). In any case, the analysis suggests that there are multiple ways to finance redistribution within the unemployment insurance system and a tax on savings or a tax on wages are not necessarily the best options. Most likely, financing mechanisms will need to be defined on a case by case basis to accommodate diverse objectives in terms of economic efficiency and equity.

The virtue of this way of framing the design of an unemployment benefit system is that it opens a continuum of choices, where classic UI and UISAs are only two particular cases that define both ends of the continuum. Thus, given a targeted level of benefits, there are multiple combinations of taxes on savings and other taxes (e.g., consumption, income, pay-roll) that can achieve financial sustainability. As discussed in the next section, these alternative financial mechanisms are likely to have different effects on the behaviors of firms and workers. The aim then is to identify the combinations that achieve the goal of providing a given level of income protection while minimizing distortions in labor markets and the economy as a whole. These combinations, of course, will be country specific. 


\section{Key policy choices in terms of design}

There are two fundamental policy choices when it comes to the design of a generic unemployment benefit system. The first is the system's mandate, which is the level of benefits or the replacement rate offered at different levels of income as well as their duration. The second is the system's financing both the level of the contribution or savings rate and the set of taxes to finance redistribution within the system. Then, depending on these policy choices, maximum limits on borrowing need to be set explicitly (by setting a maximum negative balance in the accounts) or implicitly (by having a minimum number of contributions before being able to withdraw benefits).

\subsection{Defining the mandate of the system}

The mandate of an UB system is characterized by four parameters: the replacement rate, the duration of benefits, the minimum benefit, and the ceiling on covered earnings. Clearly, there are no formulas or universal standards to set the value of these parameters; choices often reflect social preferences. There are, nonetheless, general principles one can follow to ensure that the mandate is adequate and affordable.

\subsubsection{Replacement rate and duration}

As discussed in Section 2, worldwide, both replacement rates and durations vary considerably. In general, the level of benefits offered is constrained by efficiency and welfare considerations. In terms of efficiency, a high replacement rate implies high contribution/savings rates and taxes (on savings or others). Mandatory precautionary savings that are too high can reduce incentives to enroll and provide incentives to fake dismissals (see Ribe et al. 2012; chapter 5). High taxes, in addition, can create multiple distortions -- including reducing incentives to seek and take jobs when the tax on savings is high. From the welfare side, on the other hand, the level of benefits should be sufficient to allow workers to finance consumption and job search expenditures while transiting between jobs. Depending on the tightness of the labor market and individual characteristics, these transitions can take several months. In Brazil and Mexico, for instance, male adults have lower transition rates out of non-employment and, hence, longer non-employment durations than female adults. Age and education also play a role with young workers having higher transition rates out of non-employment and, consequently, shorter non-employment spells (even if higher unemployment risks), while unskilled workers have lower transition rates, which implies longer spells (see Figure 4).

Probably, for the average worker, replacement rates would have to range between 50 and 70 percent of covered earnings while the duration ranges between 3 and 6 months. For individuals facing longer unemployment spells or at risk of becoming long-term unemployed other targeted interventions would be needed along with some form of basic unemployment assistance.

\subsubsection{Minimum benefit}

Clearly, below a given income level, even a 70 percent replacement rate might not be sufficient to maintain a basic level of consumption. Therefore, countries frequently offer a minimum unemployment benefit. Similar to the case of the replacement rate, around the world, there is a large variation in the level of this minimum. In Brazil, for instance, the minimum unemployment benefit is equal to the minimum wage. In China, 
A

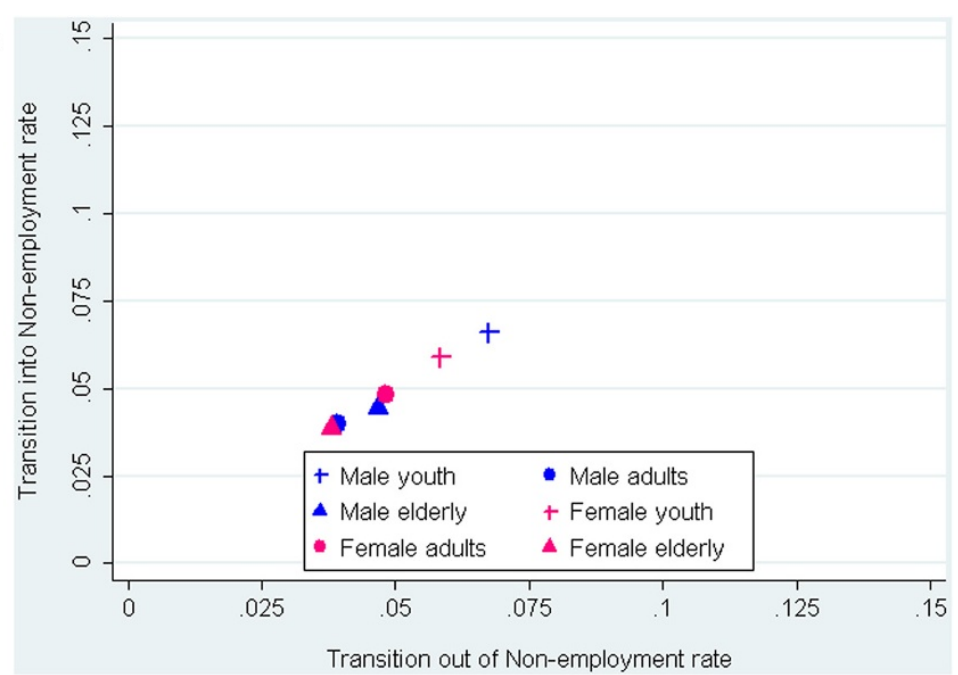

B

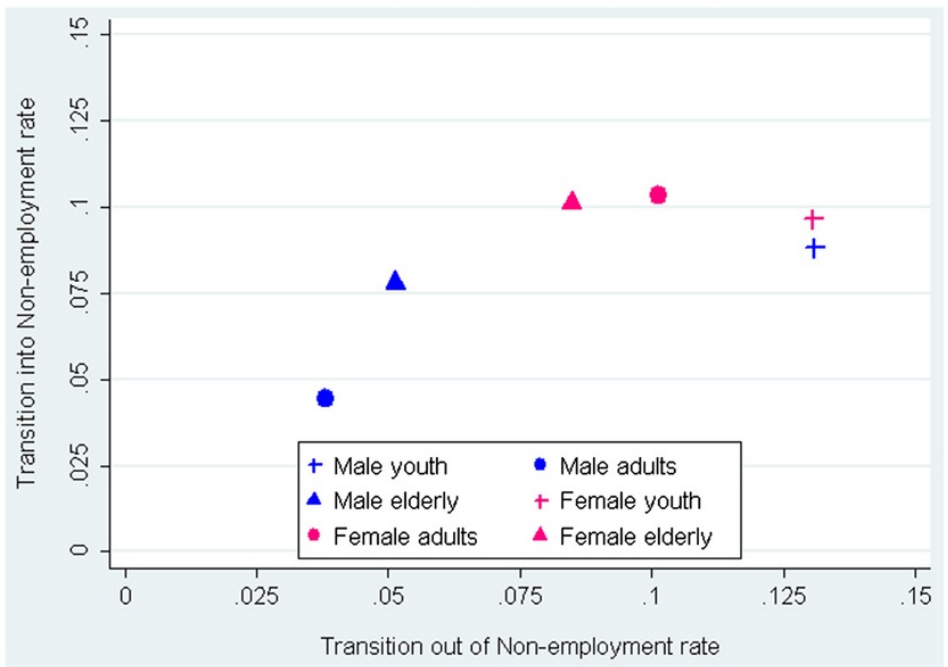

Figure 4 Transitions of and Durations of Non-Employment. (A) Brazil. (B) Mexico. Source: Authors' calculation based on PME (Brazil) and ENOE (Mexico).

depending on the region, the level of the benefit is between the minimum wage and the minimum living allowance. For example, the unemployed in the province Liaoning receive $70 \%$ of the local minimum wage if they have less than 10 years of contributions and $80 \%$ otherwise Vodopivec and Tong (2008). In other countries, such as Spain, former contributors receive unemployment benefits based on a percentage of a legally defined reference salary that increases with the number of dependents and decreases after a period of time (e.g., six months). Spain complements this regulation with a minimum noncontributory allowance for those who lost their eligibility and have an income that is smaller or equal to 75 percent of the national minimum wage.

An important policy choice is how to anchor the minimum unemployment benefit. A natural anchor would be the minimum wage. In theory, the minimum benefit would need to be below the minimum wage so that low skilled workers have stronger incentives to obtain jobs. The problem, in practice, is that the minimum wage is often subject to political discretion and can be set at levels that are 'too high'. (see Del Carpio et al. 2012 for criteria to assess the level of the minimum wage). An alternative is to 
use economy wide average earnings as a reference and target a minimum benefit that is below 30 percent of this target - also a reference for the level of the minimum wage in the literature. Clearly, this would require having an official indicator of this average.

\subsubsection{Ceiling on covered earnings}

The idea of the ceilings is to limit the mandate of the unemployment benefit system in the case of high income individuals. The presumption is that high income individuals have others sources of savings and/or insurance to manage unemployment and other risks, and that any type of redistribution within the system should focus on low income workers. A practice that has been proposed in the case of pensions is to cap covered earnings at 2.5-3 times average earnings (across countries, a very small share of workers has earnings above 3 times the average). This implies that individuals would only contribute and replace income on earnings of up to 2.5 to 3.5 times the average. Earnings above these levels would not be subject to mandatory contributions or savings.

\subsection{Financing arrangements}

As discussed above the financing of a generic unemployment benefit system has two components: an individual contribution or savings rate (part of which can be paid by the employer); and taxes used to finance redistribution (i.e., pay for the accounts with negative balances). Among the latter the options are: (i) a tax on savings; (ii) a pay-roll tax (paid by the employer); (iii) a tax on wages earned (paid by the worker and not linked to any benefit); and (iv) general revenues mobilized by other taxes.

\subsubsection{The savings or contribution rate}

For a given level of benefits, the value of the savings or contribution rate determines the share of accounts with negative and positive balances (i.e., the share of beneficiaries who receive subsidies) within a given time period, the total amount of subsidies that need to be mobilized to cover the deficits, and the total amount of savings.

One principle could be to set a contribution rate that equates liabilities and savings. This is the contribution rate that essentially equates, on average, current expenditures with current revenues (see previous section). Having a higher contribution (or savings rate) would generate too much mandatory savings (that in the case of a pure risk-pooling system are taxed at 100 percent). Having a lower contribution rate, on the other hand, would imply that general revenues (i.e., other things being equal higher taxes) are needed to subsidize negative accounts, even if taxes on savings are set at 100 percent. The recommendation therefore would be to truly treat the contribution rate as a savings rate, set it at the point where a 100 percent tax on savings suffices to balance the system, and then address the policy question of replacing part of this tax by other taxes.

\subsubsection{Taxes on savings, consumption or labor}

Knowing that at least part of the contributions that accumulate in the account can be withdrawn after a given minimum of savings is attained, or added to the pension upon retirement, can improve incentives to contribute and work. A precondition, of course, would be to ensure that savings are remunerated at a competitive rate.

In the case of classic unemployment insurance schemes, the tax on savings could be reduced by announcing to workers that part of the unemployment benefits they do not 
use would accumulate in their accounts. As discussed above, one alternative would be to ask workers to pay a percentage of their wages into a common pool, reducing each month their take-home pay. What the system would be doing, implicitly, is reducing present consumption to increase future savings. There are nonetheless various potential problems with this strategy. First, many workers might not want to substitute consumption for savings. Second, and more importantly, while the tax on wages would be paid by all workers, long-term savings would mainly be accrued by those with more stable jobs and longer contribution densities. The tax on wages could also reduce incentives to take formal jobs and, at the margin, could reduce labor supply.

Another alternative would be to finance redistribution out of pay-roll taxes or general revenues. At least from the point of view of the labor market, general revenues would be a better option, particularly if enough revenues can be mobilized without increasing 'other taxes' (see Lehmann and Muravyev 2011, Koettl and Weber 2012, Lehmann and Murvyev (forthcoming)). In essence, as indicated in Section 2, after fixing the tax on savings, any deficits of the unemployment benefit system would be covered through general revenues. This would imply budget reallocations between programs and spending categories that can have general equilibrium economic and welfare effects. Clearly, one would need to understand who are the winners and looser of such reallocations. When there are evidently inefficient or regressive expenditures, however, cutting on these to subsidize unemployment benefits could be welfare increasing.

If, at the extreme, no reallocation is possible, one alternative to the pay-roll tax would be a consumption tax. The empirical evidence about the relative level of efficiency of each of these taxes is limited. Recent studies suggest that at least in the case of economies with large informal sectors, a consumption tax is more efficient than a pay-roll tax (see Bird and Smart 2013). The idea is that at any level of the pay-roll tax it is possible to set a consumption tax that delivers the same level of real wages, economic activity, and share of formal and informal sector jobs, but that generates more revenues. The corollary is that the tax burden can be lower under a consumption tax. To avoid potentially regressive effects one alternative would be to use consumption taxes on "high-end' goods or goods with high negative externalities (e.g., cigarettes) and exempt items such as food. Other taxes that could be considered include real state taxes or taxes on financial transactions.

\subsection{Maximum limits on borrowing}

In traditional unemployment insurance schemes the eligibility for benefits - and often the level of benefits - depend on the number of months of contributions. In fact, there is usually a minimum number of contributions that is needed, for instance six months, to qualify for benefits. These eligibility conditions are ad-hoc since they do not establish a transparent link between the contributions made by individuals and the benefits they receive. Yet, they are introduced as a mechanism to control costs and abuse. It is unclear, however, that the rule makes a big difference. As an illustration, take the case of a program that requires six months of contributions to be eligible for, say, 3 months of unemployment benefits. With a contribution rate of 4 percent, under regular conditions, six months of contributions would be just enough to finance one quarter of a month's salary. Implicitly, therefore, the UI system would be allowing borrowing for as much as 2.75 months of salaries. People in this situation, once re-employed, would regain eligibility for benefits after a contribution period of six months. Those who become unemployed 
after six months would then be able to have a negative balance equivalent to 5.5 months of salaries: 2.75 minus 0.25 resulting from the new contributions plus 3 more months of benefits. So under this type of rule, individuals who contribute the minimum to receive unemployment benefits and remain unemployed for the maximum period of time would accumulate an ever growing 'debt.'

An alternative within the proposed framework is to operate under the concept of a maximum level of borrowing. For instance, workers would not be eligible for benefits if their balance in the individual account is above six months of salaries. The rule would be simpler and more transparent and, furthermore, would allow targeting individuals who are facing more structural problems when it comes to finding jobs and require special assistance. An additional rule to improve incentives is that above a given level of borrowing the contribution rate can be increased temporarily to bring down the "debt" and/or that at least part of the negative balance would be repaid at the time of retirement by reducing the pension (as long as the pension does not fall below a given threshold).

\section{Implementation}

Ultimately, the performance of any unemployment benefit system depends on implementation arrangements. One issue in the case of middle and low income countries is whether sufficient institutional capacity exists to manage the system efficiently Vodopivec (2004). ${ }^{12}$ In this section we argue that most countries can implement unemployment benefits and provide guidelines at three levels: (i) the institutional arrangement for program management and administration; (ii) conditionalities for benefit eligibility and coordination with other programs; and (iii) contracting and payment systems with providers.

\subsection{Institutional arrangements for program management and administration}

The institutional features and arrangements for unemployment compensation schemes are often neglected in policy discussions. As Atkinson and Micklewright (1991) point out, institutional details are often ignored in the literature. In particular, when applying programs from OECD contexts to developing countries a careful analysis of the necessary institutional prerequisites and arrangements is required. This is due to their diverging institutional realities with very different initial settings in areas such as administrative capacity, financial markets, as well as cultural factors.

One important policy choice is the institution which oversees the management of the system. In many cases, it might be advantageous and cost effective to make use of an institution that already deals with the relevant business processes. A natural candidate is the institution in charge of managing the national pension system which should already be handling tasks such as: identification, registration, collection of contributions, record keeping, authentication, enforcement, payment of benefits, and management of funds. The unemployment benefit system could then piggy back on the existing administrative processes.

Clearly, in many countries, the reality is that there are many problems with the administration of the pension system. Many institutions, particularly in low income settings, have not been able to keep proper records of contribution histories. At the same time, however, several countries, including low income countries such as Bolivia, have been able to 
modernize administrative systems as part of the reform of the pension system. There are also numerous examples of innovations in the administration of safety nets, including in low income settings. The implementation of conditional cash-transfers and public works programs in Pakistan as well as in Ethiopia or non-contributory health insurance in India are just three examples. We argue therefore that, if there is commitment, the introduction of unemployment benefit systems could be accompanied by the necessary reforms in terms of administrative systems.

Developing countries can also exploit recent advances in information and communication technologies to facilitate administrative tasks, including the enforcement of eligibility conditions. A key element is the unique identification, authentication, and tractability of beneficiaries and contributors. Recent technologies such biometric identification can greatly enhance the cost structure and lead to improved error, fraud, and corruption prevention. ${ }^{13}$ For example, in India, the non-contributory health insurance programs for the poor relies on biometric technologies (a smart card) to uniquely identify, authenticate, and monitor patients at much lower costs than standard approaches Paik et al. (2010). These technologies can also be applied in unemployment benefit and other income protection programs to identify, enroll, authenticate, pay, and monitor eligibility requirements. Moreover, they can be used to keep track of the services provided by those managing active labor market programs and to implement reimbursement arrangements based on results (see World Bank, forthcoming).

There are also efficiency gains that can be realized in areas such as reporting, payment of benefits, and collection of contributions. Computer and mobile applications can allow program participants to access their accounts and balances and recent transactions. Smart cards, debit cards, or mobile phone banking can in addition be used to pay benefits and collect contributions, thereby reducing costs and increasing speed, coverage, and transparency. ${ }^{14}$ By partially substituting bank services these technologies can also help reduce fees. ${ }^{15}$

\subsection{Defining and enforcing conditionalities and connecting people to jobs}

The two core conditionalities that apply to most unemployment benefit systems are: (i) not to be working; and (ii) to be actively searching for a job. In the case of middle and low income countries, enforcing either one has proven difficult. The main challenge is the high prevalence of informal jobs that renders traditional enforcement mechanisms ineffective. An alternative approach, as outlined in Robalino et al. (2009b) would be to eliminate this first condition and simply focus on ensuring that individuals receiving unemployment benefits - particularly through redistributive arrangements - engage in job search and activities to improve their employability. As discussed above, the emergence of new ICTs, including biometric ID cards, can greatly facilitate this task.

Conditionalities can come in the form of 'soft' requirements such as to search for a job or to participate in some kind of training, or in the form of 'hard' obligations as for example workfare. In both cases, the conditionalities operate under the principle of 'rights and obligations' (or 'mutual responsibilities').

In the majority of middle income countries (MIC), public employment services (PES) are pivotal for the implementation of soft requirements. These requirements may range from the simple mandatory registration with the employment service to the development of contracts that specify individual plans in terms of different activities and 
indicators that can be used to monitor progress. In some MICs, employment services are well represented and play a major role in implementation, monitoring, and enforcement. However, in many cases PES are poorly staffed and have an underdeveloped administrative and management information system which constrains their ability to effectively manage case loads and help individuals connect to jobs. The National Employment Office in Lebanon is a case in point (Robalino and Sayed, forthcoming). To avoid this scenario, an alternative might be to outsource the provision of services and enforcement of conditionalities, for example, by making use of a network of community caseworkers Almeida et al. (2012).

A generic blueprint to enforce conditionalities and help the recipients of unemployment benefits to improve their employability and connect them to jobs has been described in Ribe et al. (2012; chapter 5). The interface between the system and workers would be employment offices that can be public or private. These offices would register applications for unemployment benefits and communicate to the social security institution, which is then in charge of checking eligibility and computing benefits. The employment office would also be responsible for providing job-search assistance to beneficiaries and connecting them to certified training providers. A biometric ID card could then be used to monitor the number of hours the beneficiary spends in jobsearch or training activities. Both the employment office and training providers would weekly upload a report on services provided based on the transactions recorded by the ID Card. The social security would then use to this information to authorize the transfer of unemployment benefits to the beneficiary. For instance, transfers would only be made if the beneficiary has completed 60 or more hours of training, counseling, and job-search during the past three weeks. Key to the success of the system is, in this case, the mechanism to contract and pay providers to ensure the incentives are aligned with the objectives of the program.

\subsection{Service delivery and providers}

Service delivery, and the selection, contracting and payment of service providers are key issues when it comes to the implementation of unemployment benefits. In developed countries, concerns about the performance of (public) employment services have resulted in several reforms that introduced market mechanisms into the organization of employment services in recent years. Some of these reforms include budgeting linked to performance, management by objectives, decentralization, and the increased involvement of private sector companies combined with competitive bidding (Heyes 2011; Weishaupt 2011). The actual employment services that have so far been widely used for subcontracting in developed economies are skills training programs and increasingly also job search and placement support activities for the unemployed (Finn 2011; Thuy et al. 2001).

Sub-contracting entails the regular monitoring and evaluation of service providers and the capacity to adjust service agreements to better respond to beneficiaries and employers. Bidding procedures need to consider several dimensions, not only costs but also quality requirements. Information systems can help tracking and monitoring the performance of sub-contractors as well as labor market outcomes.

It is important to note, however, that the question of whether these additional management tasks needed for sub-contracting are justified and whether sub-contracting is 
overall cost-effective has not been answered conclusively yet. Finn (2011) cites mixed results with positive impact evaluations in the United Kingdom and no results in Germany, France, or Sweden. However, these evaluations have only been made in an early stage of private service delivery. Implementing an effective sub-contracting system for employment services is a learning process aimed at reaping the expected gains from better incentives as well as more competition and choice. This becomes a challenge in developing countries as the private sector supply of employment services might, at least initially, not be sufficient or of high quality.

Public sector involvement might therefore be required at an initial stage. It might take the form of a publicly funded service delivery platform with certain services being sub-contracted depending on the readiness and advantages of private providers. Other sensitive services such as the maintenance of a unified ID together with a centralized database on beneficiaries and contributors would naturally be kept by the public authorities. An example of a service that might be outsourced is the enrollment of beneficiaries using enrollment kits that rely on biometric IDs. Here sub-contractors could be equipped with portable enrollment kits that provide easy to use biometric identification services to a vast network of sub-contractors. ${ }^{16}$ Clearly, this kind of arrangement also needs to set appropriate incentives to maximize enrollment and define benchmarks to assess the performance of the sub-contractors. Moreover, it needs to ensure trust and minimize error, fraud, and corruption.

\section{Conclusion}

In this paper we have proposed general guidelines to design and implement (or reform) unemployment benefit programs in developing countries. Our main proposition is that the debate between risk-pooling (traditional insurance) vs. savings is misplaced. We have shown that UI and UISAs are two sides of the same coin. In both cases, administrators need to keep track of contributions and benefits. The main difference is that the savings that accumulate in some of the accounts in a UI program are used to cover the accounts that have a negative balance (savings are taxed at a 100 percent rate). Clearly, under an 'actuarially fair' risk pooling arrangement, none of the accounts would systematically accumulate savings or be in deficit. But this is not the case with traditional UI programs because plan members have different risk profiles. Given a level and duration of benefits and the contributions rate, some accounts can systematically accumulate savings (which are taxed) whereas others systematically run negative balances (which receive subsidies). These taxes and subsidies can reduce incentives to search, take, and keep jobs. At the other extreme, in the case of pure UISAs, savings are not taxed and individual accounts cannot become negative which improves incentives for job search. However, this also implies that workers are less protected against the risk of unemployment.

We propose that countries take a more flexible approach to the design of unemployment benefits. The goal should be to find a better balance between efficiency and workers protection. This is likely to be achieved by a 'hybrid' between UI and UISAs. The starting point would be to define the mandate of the program, that is the level of benefits (replacement rate and minimum benefit) to be offered at different levels of income and their duration (something that is not usually done in the case of UISAs where the benefit can be a lump sum and if it is a monthly payment the duration is 
constrained by the amount of savings in the account). The question is then how to finance the deficits that accumulate in some of the accounts. We have shown that there are four alternatives: (i) a pay-roll tax paid by employers; (ii) a tax on wages paid by workers; (iii) a tax on accounts with positive balances; and (iv) general revenues. We have argued that pay-roll taxes and taxes on wages can reduce formal employment (the latter can also be regressive relative to a tax on savings). Relying only on general revenues, on the other hand, can be considerably costly, while taxing savings at a 100 percent rate can reduce incentives to search and take jobs. The best option therefore seems to be to rely on a combination of a tax on savings (below 100 percent) and general revenues (e.g., revenues from a consumption tax, or a tax on wealth).

In terms of implementation the main messages of this paper can be summarized as follows. Countries would need to rely on current pension institutions to manage the unemployment benefit system, in order to avoid duplicating standard business process - from registration and collection of contributions to the payments of benefits. Clearly, in many cases, the administrative systems to manage pensions have deficiencies but there is evidence that these can be addressed even in the case of low income countries. The second message is that conditionalities to receive benefits should be limited to the participation in job-search and training activities and not include employment status - which is very difficult to enforce when there are large informal sectors. New technologies such as smart cards with biometric identification can be used to monitor these conditionalities. Finally, attention needs to be given to contracting and payments systems for providers of job-search assistance and training services (public or private). The goal is to give incentives to respond to the needs of job-seekers and employers. This can be achieved by making payments based on services provided (which can also be monitored based on the smart card) and results in terms of placements.

\section{Endnotes}

${ }^{1}$ For a comprehensive overview of the extensive evidence see Vodopivec (2004). A review of optimal unemployment insurance can be found for example in Karni (1999) or, more recently, Shimer and Werning (2008).

${ }^{2}$ In 'actuarially' fair risk pooling arrangements, plan members contribute a premium that reflects the expected value of their benefits. In these systems there is no systematic redistribution of income towards a group of plan members. Most social insurance programs, however, are not actuarially fair since they bring together members with different risk profiles. In this case, there is a systematic redistribution of income from some plan members to others and contributions are delinked from benefits.

${ }^{3}$ Notice that the employer could as well transfer the risks to an insurance company and pay a premium. Over a given period of time the present value of the premium and the present value of the severance paid directly should be equivalent.

${ }^{4}$ The generosity of severance pay is defined as the ratio of the number of weekly wages paid per year of service (at 1,5, and 10 years of service). An index value of larger than 2 signifies that on average a worker with equal probability to be made redundant after 1, 5 and 10 years of service would expect to receive more than 2 weeks of wage for each year worked Holzmann et al. (2011). The generosity data was calculated based 
on the World Bank's Doing Business Database on Employing Workers for 2013 (http:// doingbusiness.org/data/exploretopics/employing-workers).

${ }^{5}$ GDP per capita in current USD based on the World Bank's World Development Indicators for the year 2011 (http://data.worldbank.org/indicator/NY.GDP.PCAP.CD).

${ }^{6}$ The generosity for unemployment benefits is defined as the replacement rate for the average income worker. The data is taken from Holzmann et al. (2011).

${ }^{7}$ See Robalino et al. (2009).

${ }^{8}$ For a review and evaluation of UISA in Latin American countries, see chapter 5 in Ribe et al. (2012).

${ }^{9}$ The parameter $e_{i}$ can also be interpreted as the duration of the employment spell.

${ }^{10}$ The proof of this is as follows:

The dynamics of the total number $U_{i}$ of unemployed in group $i$ is given by:

$$
U_{i, t}=U_{i, t-1} *\left[1-\frac{1}{d_{i}}\right]+A_{i, t-1} * \frac{1}{e_{i}}
$$

where $A$ is the stock of active workers from group $i$. In steady state $U_{i, t}=U_{i, t-1}$ and $A_{i, t}=A_{i, t-1}$ so the equation above simplifies to:

$$
U_{i, t} *\left[1-1-\frac{1}{d_{i}}\right]=A_{i, t} * \frac{1}{e_{i}}
$$

Or: $\frac{U_{i, t}}{A_{i, t}}=\frac{d_{i}}{e_{i}}$

$$
\Leftrightarrow \frac{u_{i, t} * s_{i} * N}{\left(1-u_{i, t}\right) * s_{i} * N}=\frac{d_{i}}{e_{i}}
$$

$$
\Leftrightarrow \frac{u_{i}}{1-u_{i}}=\frac{d_{i}}{e_{i}}
$$

${ }^{11}$ See Brown et al. (2008).

${ }^{12}$ Fredriksson and Holmlund (2006) provide a survey of theoretical and empirical contributions on the effect of sanctions. Van der Berg et al. (2004) report significant positive effects of sanctions. Lalive et al. (2005) also show significant quantitatively similar threat effects arising from benefit sanctions on the sanctioned and nonsanctioned. Van der Klaauw and van Ours (2010) show that the outflow from unemployment doubles after sanctions have been imposed.

13 See for example the proceedings of the 2012 World Bank conference on Implementing Social Programs: "Better Processes, Better Technology, Better Results", http://go.worldbank.org/C809DRFJI0.

${ }^{14}$ An example would be the development of NADRA, Pakistan's National Database and Registration Authority).

${ }^{15}$ Brazil is an interesting example in this context. Dataprev, Brazil's technology and information bureau of the Brazilian social welfare system not only substituted the services and eliminated fees, but actually reversed the system and made the financial providers pay fees to the institution.

${ }^{16}$ Portable enrollment kits are for example provided to sub-contractors of Aadhaar, India's biometric identification system used for the provision of government services and transfers. 


\section{Competing interests}

The IZA Journal of Labor Policy is committed to the IZA Guiding Principles of Research Integrity. The authors declare that they have observed these principles.

\section{Acknowledgement}

Social Protection and Labor Unit, Human Development Network, The World Bank, Washington DC. The findings, interpretations, and conclusions expressed here are personal and should not be attributed to the World Bank, its management, its Executive Board of Directors, or any of its member countries.

Responsible editor: Juan F Jimeno

\section{Received: 12 March 2013 Accepted: 5 August 2013}

\section{Published: 24 Sep 2013}

\section{References}

Almeida R, Arbelaez J, Honorati M, Kuddo K, Lohmann T, Ovadiya M, Pop L, Sanchez Puerta ML, Weber M (2012) Improving Access to Jobs and earnings Opportunities: The Role of Activation and Graduation Policies, Background Paper to the New Social Protection and Labor. Strategy, The World Bank

Atkinson AB, Micklewright J (1991) Unemployment Compensation and Labor Market Transitions: A Critical Review. Journal of Economic Literature 29(4):1679-1727

Bird R, Smart M (2013) Financial Social Expenditures in Developing Countries: Payroll or Value Added Taxes. In: Frolich M, Kaplan D, Pages C, Rigolini J, Robalino D (eds) Social Insurance and Labor Markets: How to protect workers while creating new jobs. Oxford University Press, forthcoming

Brown AJG, Orszag JM, Snower DJ (2008) Unemployment Accounts and Employment Incentives. European Journal of Political Economy 24(3):587-604

Chetty R (2004) Optimal unemployment insurance when income effects are large, NBER Working Paper 10500

Chetty R (2008) Moral Hazard versus Liquidity and Optimal Unemployment Insurance. Journal of Political Economy 116(2):173-234

Chetty R, Looney A (2006) Consumption smoothing and the welfare consequences of social insurance in developing economies. Journal of public economics 90(12):2351-2356

Del Carpio X, Nguyen H, Wang LC (2012) Does the Minimum Wage Affect Employment? Evidence from the Manufacturing Sector in Indonesia, Policy Research Working Paper 6147. Washington, DC, The World Bank

Finn D (2011) Sub-contracting in public employment services: Review of research findings and literature on recent trends and business models, DG Employment and Social Affairs and. Inclusion, European Commission

Fredriksson P, Holmlund B (2006) Improving Incentives in Unemployment Insurance: a Review of Recent Research. Journal of Economic Surveys 20(3):357-386

Heyes I (2011) Labour ministries and Labour Administration in Transition: Recent Developments and Future Prospects, Working Document Number 16, Labour Administration and Inspection Programme. International Labour Organization, Geneva

Holzmann R, Pouget Y, Vodopivec M, Weber M (2011) Severance Pay Programs Around the World: History, Rationale, Status, and Reforms. IZA Discussion Paper No. 5731, Institute for the Study of Labor (IZA)

Karni E (1999) Optimal unemployment insurance : a guide to the literature, Social Protection Discussion Papers 20121. The World Bank

Koettl J, Weber M (2012) Does Formal Work Pay? The Role of Labor Taxation and Social Benefit Design in the New EU Member States. Research in Labor Economics 34:167-204

Lalive R (2008) How do extended benefits affect unemployment duration A regression discontinuity approach. Journal of Econometrics, Elsevier 142(2):785-806

Lalive R, van Ours JC, Zweimüller J (2005) The Effect of Benefit Sanctions on the Duration of Unemployment. Journal of the European Economic Association 3(6):1386-1417

Lehmann H, Muravyev A (2011) Labor Market Institutions and Labor Market Performance: What Can We Learn from Transition Countries? IZA Discussion Paper No. 5905, Institute for the Study of Labor (IZA)

Lehmann H. Muravyev A (forthcoming) Labor Market Institutions and Informality in Transition and Latin American Countries. In: Frolich M, Kaplan D, Pages C, Rigolini J, Robalino D (eds) Social Insurance and Labor Markets: How to protect workers while creating new jobs. Oxford University Press, forthcoming

Paik M, Samdaria N, Gupta A, Weber J, Bhatnagar N, Batra S, Bhardwaj M, Thies W (2010) A biometric attendance terminal and its application to health programs in India. In Proceedings of the 4th ACM Workshop on Networked Systems for Developing Regions (NSDR '10), ACM, New York, NY, USA, pp 4-6

Ribe H, Robalino D, Walker I (2012) From Right to Reality: Incentives, Labor Markets, and the Challenge of Universal Social Protection in Latin America and the Caribbean. World Bank, Washington, DC

Robalino D, Sayed H (forthcoming) Lebanon: Good Jobs Wanted, Mimeo, Human Development Department, Middle East and North Africa Region. The World Bank, Washington, DC

Robalino D, Vodopivec M, Bodor A (2009) Savings for unemployment in good or bad times: options for developing countries. IZA Discussion Paper No. 4516, Institute for the Study of Labor (IZA)

Shimer R, Werning I (2008) Liquidity and Insurance for the Unemployed, American Economic Review, American Economic Association. 98(5):1922-42

Tatsiramos K (2009) Unemployment Insurance in Europe: Unemployment Duration and Subsequent Employment Stability. Journal of the European Economic Association 7(6):1225-1260

Thuy P, Hansen E, Price D (2001) The Public Employment Service in a Changing Labour Market. International Labour Organisation, Geneva

Van den Berg G, van der Klaauw B, van Ours JC (2004) Punitive Sanctions and the Transition Rate from Welfare to Work. Journal of Labor Economics 22(1):211-41

Van der Klaauw B, van Ours JC (2010) Carrot and Stick: How Reemployment Bonuses and Benefit Sanctions Affect Job Finding Rates, IZA Discussion Paper 5055 
Vodopivec M (2004) Income Support for the Unemployed: Issues and Options. Regional and Sectoral Studies, The World Bank, Washington, DC

Vodopivec M, Tong MH (2008) China: Improving Unemployment Insurance, Social Protection Discussion Paper 44779 The World Bank, Washington, DC

Weishaupt TJ (2011) Social Partners and the Governance of Public Employment Services: Trends and Experiences from Western Europe, Working Document Number 17, Labour Administration and Inspection Programme. International Labour Organization, Geneva

World Bank (2009) Social Insurance and Labor Supply: Assessing Incentives and Redistribution, Technical Report. The World Bank, Washington, DC

World Bank (2012) World Development Indicators 2012. The World Bank, Washington, DC

World Bank (2013) Doing Business Database 2013: Doing Business in a More Transparent World. The World Bank, Washington, DC

World Bank (forthcoming) Creating Good Jobs in Tunisia, Country Report. The World Bank, Washington DC

\subsection{6/2193-9004-2-12}

Cite this article as: Robalino and Weber: Designing and implementing unemployment benefit systems in middle and low income countries: beyond risk-pooling vs savings. IZA Journal of Labor Policy 2013, 2:12

Submit your manuscript to a SpringerOpen ${ }^{\circ}$ journal and benefit from:

- Convenient online submission

- Rigorous peer review

- Immediate publication on acceptance

- Open access: articles freely available online

- High visibility within the field

Retaining the copyright to your article

Submit your next manuscript at $\boldsymbol{~ s p r i n g e r o p e n . c o m ~}$ 